\title{
Effects of Environmental Surface Modification Methods on Physical Properties of Hemp Fibers
}

\author{
Nigar MERDAN * \\ Istanbul Commerce University, Faculty of Design and Engineering, Department of Textile Engineering, Kucukyali/Istanbul- \\ TURKEY \\ crossref http://dx.doi.org/10.5755/j01.ms.23.4.17469
}

Received 24 January 2017; accepted 23 March 2017

\begin{abstract}
In this study, hemp fibers have been pre-treated with laccase enzyme in different concentrations $(1 \%, 2 \%$ and $3 \%$ w/v) for different durations using conventional, ultrasonic energy and microwave energy methods. Weight loss (\%), tensile strength, elongation (\%), whiteness (\%), and surface topography (SEM) properties of pre-treated hemp fibers were investigated. After processing with laccase enzyme, the energy consumptions of these three methods were compared. Best results have been obtained in 20 minutes with the conventional method, 5 minutes with the ultrasonic energy method, and 1 minute with the microwave energy method. With laccase enzyme, microwave treated hemp fibers were improved after 3 minutes treatment. SEM results have also proved the improved physical properties and color changes due to the rough surface structure.
\end{abstract}

Keywords: hemp fiber, laccase enzyme, surface treatment.

\section{INTRODUCTION}

Cellulose-based fibers have been finding a place in the field of several industrial uses because of their advantages such as low prices, recyclability, and biodegradability [1]. Because of having good UV resistance, mechanical (specific strength, modulus etc.) and antibacterial properties, and low density; hemp fibers have been heavily used in production of fabrics, apparel, bags and socks in textile; for cordage, netting, canvas, and carpeting production in technical textiles; and in plastic, automotive, and packaging industries [2]. Hemp fibers are lignocellulose-based fibers and contain $\sim 67 \%$ cellulose, $\sim 16 \%$ hemicellulose, $\sim 0.8 \%$ pectin, $\sim 3.3 \%$ lignin, and $\sim 0.7 \%$ fats and waxes in its chemical structure. Therefore hemp fibers have been applied chemical pre-treatments, as they need their wetness properties to be improved in order to increase their usage as textile surfaces. Treatment with sodium hydroxide $(\mathrm{NaOH})$ is mostly used to improve wetness properties of hemp fibers. By alkali treatments, the mechanical [3] and water uptake [4] properties of hemp fibers have been improved. Wetness is the critical function for most of the textile finishing processes. This feature is necessary not only for the final use of the product but also for dyeing and finishing processes.

The enzyme technology is an environmental method; for this reason, it is used in a lot of areas like medicine, pharmacy, agriculture, farming, environment, food, paper, detergent and textile industries. It's widely believed that enzymes will be controlled by biotechnology in textile pretreatments in the future [5]. Novozymes (Novo Nordisk, Denmark) first used laccase enzyme in industry for denim finishing in 1996. Denilite ${ }^{\circledR}$ is the first industrial laccase enzyme and the first bleaching enzyme moving with the help of a mediator. Laccase enzymes have been used in removing the oils, waxes, pectins, proteins and pigments which are natural colouring materials from the cellulosic fibers [6], in denim washing [7], in boiling processes [8], in dyeing, printing and finishing processes, and in biological degradation and decolorization of textile wastewaters [9]. Using environmental friendly methods is very important as using environmentally friendly chemicals in surface modifications of hemp fibers. In this study, ultrasonic energy and microwave energy methods have been used as alternative methods to the conventional method. Ultrasound has a sonic spectrum range between $20 \mathrm{kHz}$ and $10 \mathrm{MHz}$. Ultrasonic energy is occurred by rising microscopic bubbles known as cavitation [10]. Cavitation has chemical and mechanical effects. For example decomposing of high molecular mass by dispersion effect, and carries the chemicals to the capillaries of the fibers by degassing effect, these processes are performed by consuming low energy, low substances and in short time [11]. The ultrasonic energy method has been widely used in textile industry for bleaching and dyeing as a green and environmental technology [12-18].

Microwaves are the radio waves with high frequencies between $30 \mathrm{MHz}$ and $30.000 \mathrm{MHz}$. Microwave energy is easy to use in drying, dyeing, printing and in various processes of the textile industry because of its quick and economic heating properties [19]. In order to apply microwave energy method to a product, it should have a dielectric loss and it is necessary to generate dipolar electric charges in the material when a variable electromagnetic field is applied. Thus water molecules can easily form dipolar electric charges, so water containing structures or structures in an aqueous medium are suitable for microwave heating. The microwave energy method is described as an environmentalist method for accelerating chemical processes and especially for energy and time-saving in

${ }^{*}$ Corresponding author. Tel.: +90-543-3429650.

E-mail address: nmerdan@ticaret.edu.tr (N. Merdan) 
reactions. Using of microwave technology in textile finishing is related to the application, research and development studies which enclose application areas of heating up, drying, condensation, dyeing, and printing [20]. It is revealed that the microwave energy method is an environmental method for using in textile finishing, polyester dyeing [21], coloring flax fiber [22], surface treatments of cellulose and protein based fibers [23-25].

In this study, surface modifications with laccase enzyme having different concentrations have been applied to hemp fibers for different durations. The conventional, ultrasonic energy and microwave energy methods have been compared. We have observed that the eco-friendly microwave energy method had positive effects and improved the weight loss, tensile strength and elongation properties of hemp fibers. Also, the ultrasonic energy method improved whiteness values of hemp fibers while gaining energy consumption.

\section{EXPERIMENTAL}

\subsection{Materials}

\subsubsection{Fibers}

We used untreated hemp fibers. The physical properties of hemp fibers are given in Table 1.

Table 1. Physical properties of hemp fibers

\begin{tabular}{|l|c|c|c|}
\hline \multicolumn{1}{|c|}{ Properties } & Hemp fiber & SD & CV \\
\hline Diameter, $\mu \mathrm{m}$ & 10.87 & 15.3 & 15.1 \\
\hline Tensile strength, gF & 73.3 & 26 & 11.2 \\
\hline Elongation, \% & 5.2 & 13.7 & 10.6 \\
\hline \multicolumn{4}{|l|}{ SD - standard Deviation; CV - coefficient of variation } \\
\hline
\end{tabular}

\subsubsection{Chemicals}

The laccase enzyme, used in this study, was an EC 1.10.3.2 Trametes Versicolor based biochemical and obtained from the company Novozymes. It was indicated that its containing laccase activity was $20 \mathrm{unit} / \mathrm{mg}$. It was also mentioned by the company that 1 unit was the enzyme amount that was necessary for transforming $1 \mu \mathrm{mol}$ catechol at $\mathrm{pH} 4.5$ per minute. It was in powder form.

\subsection{Methods}

In this study, works have been held with laccase enzyme having three different concentrations (1\%, $2 \%$ and $3 \% \mathrm{w} / \mathrm{v}$ ) at $\mathrm{pH} 4.5$ by three different methods. $10 \mathrm{~g}$ hemp fiber samples have been used for each method. Each method has been repeated for three times. The conventional atmospheric method was performed at $60{ }^{\circ} \mathrm{C}$ for 20,30 and 40 minutes (in laboratory conditions with EMSEY Teknik sample dyeing machine at $3000 \mathrm{~W}$ and $220 \mathrm{~V}$ ), the ultrasonic energy method was performed at $60{ }^{\circ} \mathrm{C}$ for 10,15 and 20 minutes with using Alex ultrasonic washing bath $(220 \mathrm{~V}, 660 \mathrm{~W}$, and $40 \mathrm{kHz})$, and the microwave energy method was performed by using Kenwood MW 440 microwave machine at a frequency of $2.45 \mathrm{GHz}$. The experiments have been carried out using microwave oven with a medium power of $800 \mathrm{~W}$ at six discrete settings for 1,3 and 5 minutes at $98{ }^{\circ} \mathrm{C}$. The hemp fibers having surface modifications done (at $80{ }^{\circ} \mathrm{C}$ for 10 minutes at $\mathrm{pH} 7$ rinsed with distilled hot water) have been dried at room conditions.

\subsection{Measurements and standards}

\subsubsection{Weight loss}

The weight loss was determined on atmospherically conditioned fibers after different treatment processes. The determination of weight loss has been done in accordance with ASTM D1695-07(2012). The weight loss percentage $\left(W_{j}\right)$ is calculated from the differences in weight using the following:

$W j=\frac{\text { Wpre }- \text { Wafter }}{\text { Wpre }} \times 100(\%)$,

where $W_{\text {pre }}$ was the weight of the conditioned fibers prior to pre-treatment, and $W_{\text {after }}$ was the weight after performed pretreatment.

\subsubsection{Whiteness index}

The quality of bleached products can be defined by their whiteness, provided that only the values obtained by the same method were taken into account in the relative evaluation of a series of products. The whiteness of each pre-treated and chemically bleached samples was evaluated on the basis of the following CIE equation under D65 illuminant for $10^{\circ}$ and $20^{\circ}$ standard observers). The determination of CIE Whiteness of the treated samples has been done in accordance with AATC 110-2005. CIE Whiteness Index is formulated as shown below:

$$
\begin{aligned}
& W I=Y+800\left(x_{\mathrm{n}}-x\right)+1700\left(y_{\mathrm{n}}-y\right) \\
& W I_{10}=Y_{10}+800\left(x_{\mathrm{n}, 10}-x_{10}\right)+1700\left(y_{\mathrm{n}, 10}-y_{10}\right) .
\end{aligned}
$$

In this equation $x, x_{10}, Y, y_{10}$ are the colorimetric values found by using of $10^{\circ}$ and $20^{\circ}$ standard observer values under D65 illuminant. $x_{\mathrm{n}}, x_{\mathrm{n}, 10}$, and $y_{\mathrm{n}}, y_{\mathrm{n}, 10}$ are the cromatisite coordinates of D65 illuminant belonging to $10^{\circ}$ and $20^{\circ}$ standard observers. The ideal reflecting property of Whiteness Index of diffusioner is 100.0.

\subsubsection{Morphological properties}

The morphological (SEM) properties of the samples were analyzed with JEOL JSM-T330 instrument, which has been operated at $5 \mathrm{kV}$ and $10 \mathrm{kV}$, according to TS EN ISO 9220 standard. The samples were coated with gold.

\subsubsection{Energy values}

The results of energy values have been calculated via the equation given below:

$E=P . T$,

where $E$ is the energy consumption, $P$ is the power (W), $T$ is the time $(h)$.

\subsubsection{Characterization}

Fiber examples were conditioned at room temperature ( $20{ }^{\circ} \mathrm{C}$ and with $65 \%$ relative humidity) for at least 24 hours before performing the characterization tests. Fiber samples were randomly taken from hemp fibers, and 50 measurements were performed. Tensile strength and elongation properties of the fibers were tested according to 
ASTM 3822 by using Instron 4411 Model. Samples were dried by hanging at laboratory conditions, and then whiteness properties have been measured. Macbeth Color Eye (Gretag Macbeth) spectrophotometer was used for whiteness measurements at $\mathrm{D} 65 / 10^{\circ}$, and the averages of the measurements taken from 3 different points of the samples were evaluated.

\section{RESULTS AND DISCUSSION}

\subsection{The results of weight loss properties}

Fig. 1 shows the change in weight loss values of hemp fibers after conventional, ultrasonic energy and microwave energy method treatments for different durations. When the increase at weight loss values have been evaluated, the highest weight loss has been observed with $2 \%$ concentration at 40 minutes in the conventional method, with $3 \%$ concentration at 15 minutes in the ultrasonic energy method, and with $2 \%$ concentration at 3 minutes in the microwave energy method. Within these three methods, the microwave energy method caused contaminants on hemp fiber surfaces removed by etching in a short period of time. The reason for such observation was the removal of residual size materials and impurities from the fibers during microwave energy treatment. Weight loss values of hemp fibers having the microwave energy treatment were higher than the values of hemp fibers having the treatment with conventional method [26]. Biljana M. Pejic et al (2008) have observed the most weight loss as $9.9 \%$ with $17.5 \% \mathrm{NaOH}$ concentration at 45 minutes with the conventional method. In this study, we have observed the most weight loss as $8.1 \%$ with $2 \%$ laccase enzyme concentration at 3 minutes with microwave energy method. This improvement has been obtained in a shorter time period and also with an ecofriendly and an environmental method.

\subsection{The results of tensile strength properties}

As shown in Fig. 2, the tensile strength value of untreated hemp fibers was higher than the tensile strength values of hemp fibers treated with laccase.

In the conventional method, the tensile strength values of hemp fibers were decreasing due to the increase in concentration and duration. The best tensile strength values were observed with $2 \%$ concentration at 30 minutes in the conventional method, with $3 \%$ concentration at 15 minutes in the ultrasonic energy method, and with $2 \%$ concentration at 2 minutes in the microwave energy method. The tensile strength value obtained with the microwave energy method had $4.3 \%$ more increase than the tensile strength value obtained with the ultrasonic energy method. This was because laccase enzyme has been penetrated by affecting the hemp fibers in a short period of time in the microwave energy method. And also in the microwave energy method, the fiber surfaces have been damaged less than in other methods [27].

Yan Li et al (2009) had observed a $21.9 \%$ decrease in tensile strength value of the samples treated with the conventional method at 6 hours.

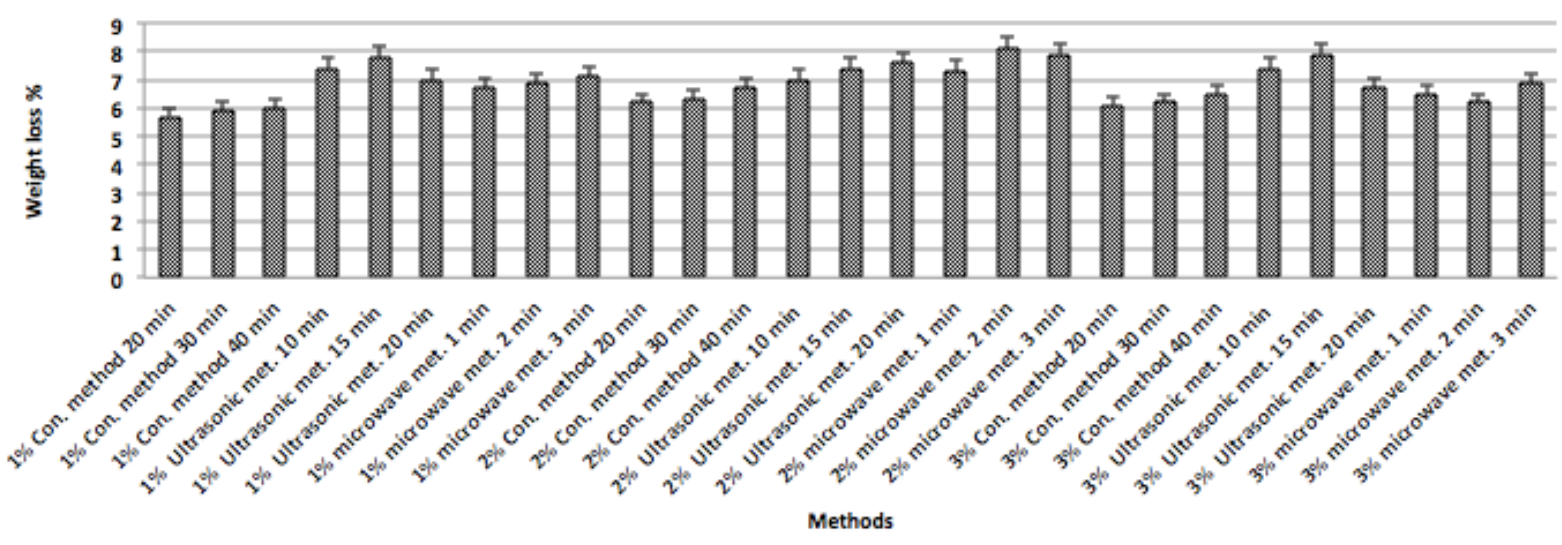

Fig. 1. Changes in weight loss as a result of laccase treatment

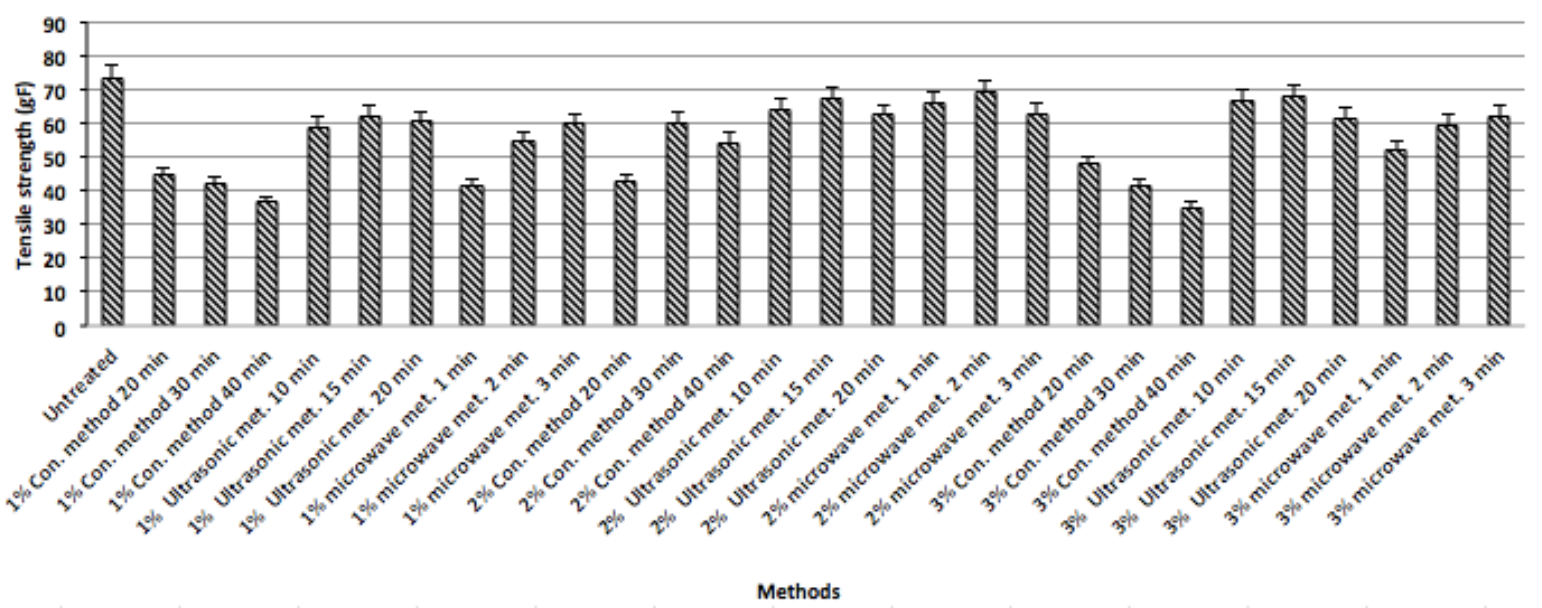

Fig. 2. Changes in tensile strength behavior as a result of laccase treatment 
In this study, we have observed a $5.5 \%$ decrease in tensile strength of a single fiber treated with $2 \%$ laccase enzyme concentration at 2 minutes with microwave energy method. Less tensile strength decrease has been obtained in a shorter time with a more eco-friendly and environmental method.

\subsection{The results of elongation properties}

In Fig. 3 the elongation of untreated hemp fiber was $5.2 \%$. The elongation values increased due to the increase in laccase enzyme concentration.

The highest elongation value $(7.9 \%)$ in the ultrasonic energy method has been observed with $3 \%$ concentration at 15 minutes. The effect of the ultrasonic energy has increased penetration of laccase enzyme into the fiber through the bubbles that the sonication power reveals. Thus, the laccase enzyme, which entered the fibers in a short time, affected the elongation properties of the hemp fibers. The highest elongation \% value $(7.6 \%)$ in the microwave energy method has been observed with $3 \%$ concentration at 3 minutes. The microwave energy method was more rapid, uniform and efficient than other two methods. In our previous study, we have observed that laccase enzyme has quickly affected the fiber structure of raffia-based fabric in a shorter time with the microwave energy method [28].

\subsection{The results of whiteness properties}

In Fig. 4 the whiteness value of untreated hemp fibers is $20.2 \%$. The whiteness values increased due to the increase in laccase enzyme concentration.
The whiteness value of hemp fibers, treated with $3 \%$ concentration of laccase for 3 minutes in the microwave energy method, was 39,5\% higher than the whiteness value of untreated hemp fibers. The highest whiteness value was observed as $31.2 \%$ with $3 \%$ concentration of laccase for 20 minutes in the ultrasonic energy method, and as $27.8 \%$ with $3 \%$ concentration of laccase for 40 minutes in the conventional method. The best whiteness value obtained with decreasing the processing time was observed in the ultrasonic energy method. A. Abou-Okul et al (2010) had observed whiteness as $1.9 \%$ in samples treated with $3 \%$ laccase enzyme concentration at 30 minutes in ultrasonic energy method [29]. This was because, the ultrasonic energy spread into the hemp fibers in the form of energy vibrations caused by microbubbles, so that the laccase enzyme fibers have been more easily diffused into the fibers.

\subsection{SEM analysis}

The surface topographies of untreated hemp fibers are shown in Fig. 5 a. The surface topographies of hemp fibers, treated for 40 minutes in the conventional method, are shown in Fig. 5 b, and the surface topographies of hemp fibers treated for 15 minutes in the ultrasonic energy method and for 5 minutes in the microwave energy method are shown in Fig. $5 \mathrm{c}$ and $\mathrm{d}$.

Laccase enzyme with $3 \%$ concentration with the ultrasonic energy method has affected the surface of the hemp fibers. Because of the cavitation caused by the ultrasonic energy, the laccase enzyme with large molecules has been rapidly broken down, and this made it easier to penetrate into the fiber.

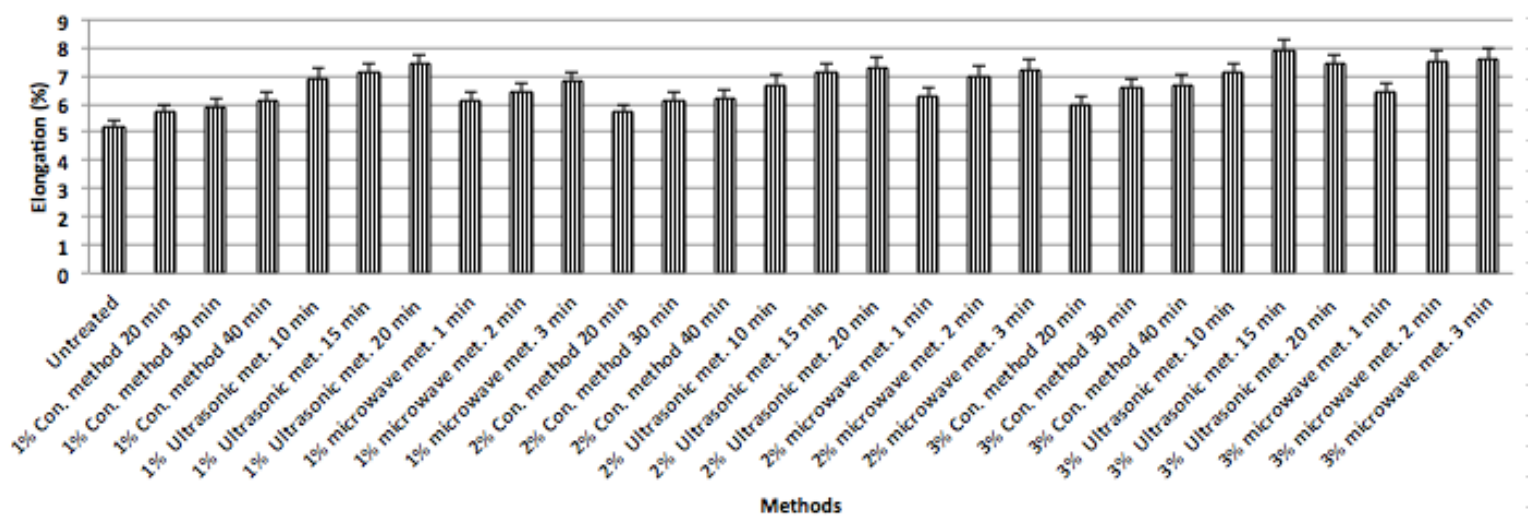

Fig. 3. Changes in elongation behavior as a result of laccase treatment

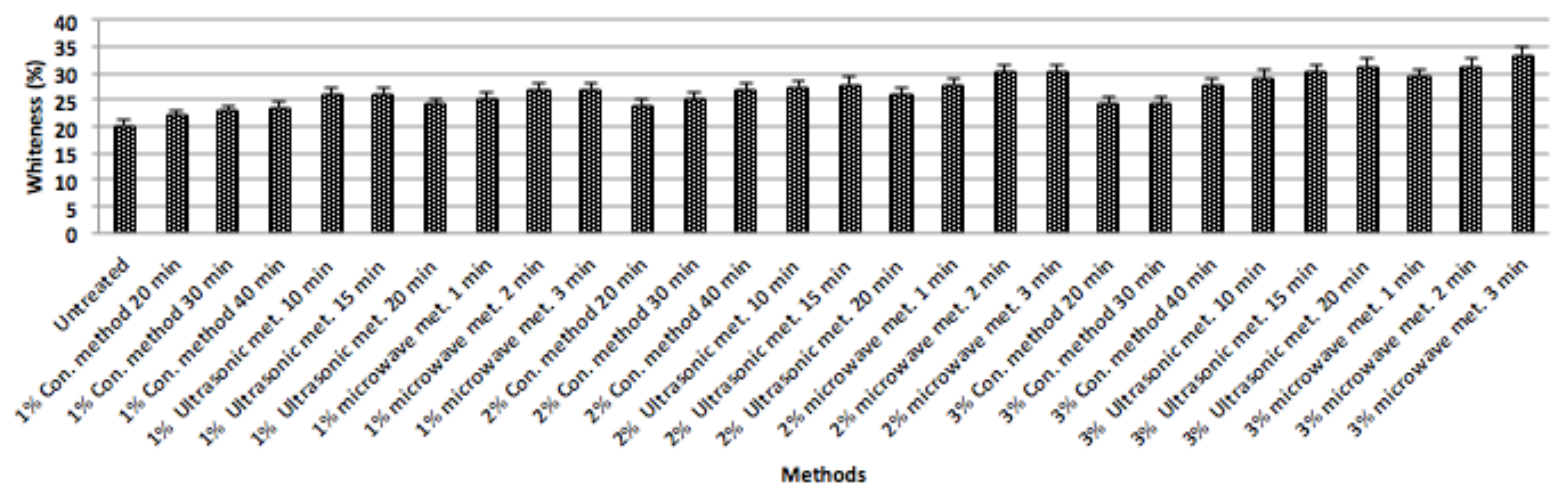

Fig. 4. Changes in whiteness behavior as a result of laccase treatment 


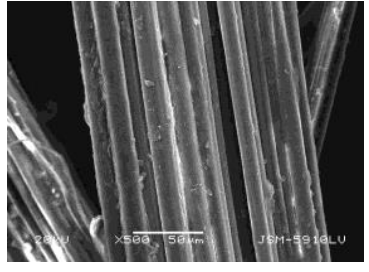

a

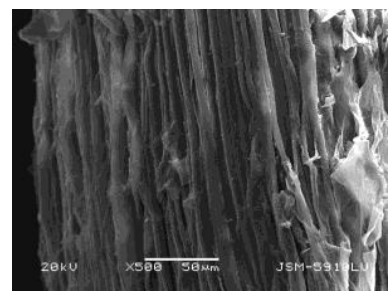

c

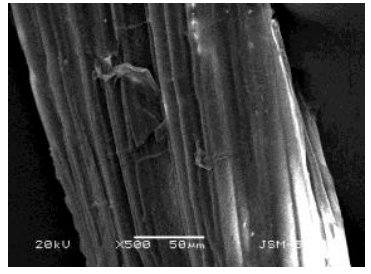

$\mathrm{b}$

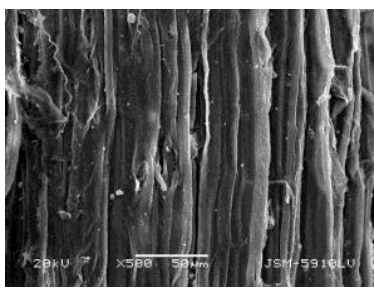

d
Fig. 5. The surface topographies of hemp fibers as a result of laccase treatment: a - untreated hemp fibers; $b$-hemp fibers with $3 \%$ laccase enzyme treated in the conventional method (40 minutes); c-hemp fibers with $3 \%$ laccase enzyme treated in the ultrasonic energy method (15 minutes); $\mathrm{d}$-hemp fibers with $3 \%$ laccase enzyme treated in the microwave energy method ( 3 minutes)

Therefore, the contaminants and waxes have been removed from the fiber surface effectively [30]. So it was also effective in fibrillation at the surface of hemp fibers.

Laccase enzyme treatment with the microwave energy method was more effective on the morphology of hemp fibers. The outer layers of parenchyma cells have been removed to expose the inner fibers. Fig. $5 \mathrm{~d}$ shows that the outer layer of hemp fibers was mostly removed by using the microwave energy method [29, 31].

\subsection{Result of energy values}

In this study, the energy consumption values of these three modification methods, as shown in Table 3, have been compared. It was observed that the energy consumptions increased due to the increase in processing durations.

Table 3. The comparison of energy consumptions of the methods used in surface modifications of hemp fibers

\begin{tabular}{|l|c|c|}
\hline \multicolumn{1}{|c|}{ Methods } & $\begin{array}{c}\text { Output } \\
\text { power, } \mathrm{W}\end{array}$ & $\begin{array}{c}\text { Energy } \\
\text { consumption, } \\
\mathrm{W} / \mathrm{h}\end{array}$ \\
\hline 20 min conventional treatment & 3000 & 1000 \\
\hline 30 min conventional treatment & 3000 & 1500 \\
\hline 40 min conventional treatment & 3000 & 2000 \\
\hline 10 min ultrasonic treatment & 660 & 110 \\
\hline 15 min ultrasonic treatment & 660 & 174 \\
\hline 20 min ultrasonic treatment & 660 & 220 \\
\hline 1 min microwave treatment & 800 & 13.3 \\
\hline 3 min microwave treatment & 800 & 26.7 \\
\hline 5 min microwave treatment & 800 & 40 \\
\hline
\end{tabular}

However, the energy consumptions decreased due to the decrease in processing time and power used. In terms of energy consumption, it is seen that the least energy consuming environmental method was the microwave energy method [32].

\section{CONCLUSIONS}

The three surface modification methods, which were applied with three different concentrations of laccase enzyme for three different durations, done on hemp fibers have been compared. According to this:

1. In applications with the conventional method, the surface modifications with higher laccase enzyme concentrations and longer durations were more effective. But in the ultrasonic energy method, with the effect of cavitation, the surface modifications with lower enzyme concentrations and shorter durations were more effective. In elongation and whiteness, its positive effects have been observed.

2. In applications with the microwave energy method, the surface modifications with lower laccase enzyme concentrations and shorter durations were more effective. In the microwave energy method, an increase was observed in tensile strength values according to other methods. The reason was laccase enzyme has been penetrated into the hemp fibers by affecting them quickly in the microwave heating method. In this method, the surface of the hemp fibers have been less damaged than in other two methods, and an increase has been observed in tensile strength and weight loss values. SEM results were proved the improved physical properties due to the rough surface structure.

3. In the microwave energy method applications, it has been revealed that the microwave energy method was an environmentally friendly method with shorter process durations, less chemical usages, and lower energy consumptions.

4. In the surface modification of hemp fibers, it has been observed that the microwave energy and ultrasonic energy methods consumed less energy in shorter time periods than the conventional method. Also when the two eco-friendly methods were compared, it has been found that time and energy consumptions of microwave energy method were less than the ultrasonic energy method.

\section{REFERENCES}

1. Mohanty, A.K., Misra, M., Hinrichsen, G. Biofibres, Biodegradable Polymers and Biocomposites: an Overview Macromolecular materials and Engineering $276(1)$ 2000: pp. $1-24$.

2. Frederick, Tw., Norman, W. Natural Fibers Plastics and Composites, Kluwer Academic Publishers, New York 2004.

3. Pejic, B.M., Kostic, M.M., Skundric, P.D., Praskalo, J.Z. The Effects of Hemicelluloses and Lignin Removal on Water Uptake Behaviour of Hemp Fibers Bio Resource Technology 99 2008: pp. $7152-7159$.

4. Bismarck, A., Askargorta, I.A., Springer, J., Lampke, T., Wielage, B., $\quad$ Stamboulıs, A., $\quad$ Shenderovich, I., Limbach, H.H. Surface Characterization of Flax, Hemp and Cellulose Fibers; Surface Properties and the Water Uptake Behaviour Polymer Composites 23 (5) 2002: pp. $872-894$.

5. Couto, S.R., Herrera, J.L.T. Industrial and Biotechnological Applications of Laccases: A Review Biotechnology Advances 24 2006: pp. 500-513. https://doi.org/10.1016/j.biotechadv.2006.04.003 
6. Basto, C., Tzanov, T., Cavaco-Paulo, A. Combined Ultrasound-Laccase Assisted Bleaching of Cotton Ultrasonics Sonochemistry 14 2007: pp. 350-354.

7. Yoon, M.Y. Denim Finishing with Enzymes-Biobleaching with Laccase and Mediator International Dyer 12 2005: pp. $1-3$.

8. Parshetti, G.K., $\quad$ Kalme, S.D., Gomare, S.S., Govindwar, S.P. Biodegradation of Reactive Blue- 25 by Aspergillus Ochraceus NCIM-1146 Bio Resource Technology 98 2007: pp. 3638-3642. https://doi.org/10.1016/j.biortech.2006.11.017

9. Kumanneni, A., Ghazi, I., Camarero, S., Ballesteros, A., Plou, F.J., Alcalde, M. Decolorization of Synthetic Dyes by Laccase Immobilized on Epoxy-Activated Carriers Process Biochemistry 43 2008: pp. 169-178. https://doi.org/10.1016/j.procbio.2007.11.009

10. Niaz, A., Moshin, F., Kaleem, U., Kashif, R., Afia, S.A., Ishaq, B.I Ultrasonic-Assisted Pre-Treatment of Cotton Textiles Dyeing Printing Finishing 2011: pp. 37-39.

11. Vajnhandl, S., Le Marechal, A.M. Ultrasound in Textile Dyeing and the Decolouration/Mineralization of Textile Dyes Dyes Pigment 65 (2) 2005: pp. 89-101.

12. Yachmenev, V.G., Bertoniere, N.R., Blanchard, E.J. Effect of Sonication on Cotton Preparation with Alkaline Pectinase Textile Research Journal 71 (26) 2001: pp. $527-533$.

13. Akalin, M., Merdan, N., Kocak, D., Usta, I. Effects of Ultrasonic Energy on the Wash Fastness of Reactive Dyes Ultrasonics $42(1-9)$ 2004: pp. 161-164.

14. Merdan, N., Akalin, M., Kocak, D., Usta, I. Effects of Ultrasonic Energy on Dyeing of Polyamide (Microfibre)/Lycra Blends Ultrasonics 42 (1-9) 2004: pp.165-168.

15. Kocak, E.D. The Influence of Ultrasonic Energy on Chemical Treatment of Surface Properties and the Properties of Composites Made of Luffa Cylindrical Fiber-Polyester Resin Journal of Engineering Materials and Technology 130 (4) 2008: pp. 1-7.

16. Kocak, D. Study of the Effects Different Chemical Compound Applied on Luffa Cylindrical Fibres with the Help of Ultrasonic Energy Journal of Polymer Engineering 28 (8) 2008: pp. 501-515.

17. Merdan, N., Sahinbaskan, B.Y., Kocak, D. Colour and Fastness Properties of Silk Fabrics Dyed with Colours Obtained from the Flowers of the Papaver Rhoeas L. (Common Poppy) Asian Journal Of Chemistry 24 (10) 2012: pp. 4295 - 4299.

18. Merdan, N., Inanici, Y. Use of Ultrasonic Energy in Dyeing of Microfiber Asian Journal of Chemistry 24 (3) 2012: pp. $969-974$.
19. Atav, R. The Use of New Technologies in Dyeing of Proteinous Fibers, Eco-Friendly Textile Dyeing and Finishing Book, 2013, Chapter 5. https://doi.org/10.5772/53912

20. Vouters, M., $\quad$ Rumeau, P., $\quad$ Tierce, $\mathbf{P}$., $\quad$ Costes, $\mathbf{S}$. Ultrasounds: an Industrial Solution to Optimise Costs, Environmental Requests and Quality for Textile Finishing Ultrasonics Sonochemistry 2004: pp. 33-38.

21. Soo Kim, S., Gyung Leem, S., Do Ghim, H., Ho Kim, J., Seok Lyoo, W. Microwave Heat Dyeing of Polyester Fabric Fibers and Polymers 4 (4) 2003: pp. 204-209. https://doi.org/10.1007/BF02908280

22. Sun, H., Lin, L., Jiang, $\mathbf{X}$., Bai, $\mathbf{X}$. The Improvement of Dyeability of Flax Fibre by Microwave Treatment Pigment \& Resin Technology 34 (4) 2005: pp. 190-196.

23. Kocak, D., Merdan, N., Yuksek, M., Sancak, E. Effects of Chemical Modifications on Mechanical Properties of Luffa Cylindrica Asian Journal of Chemistry 25 (2) 2013: pp. 637-641.

24. Merdan, N., Sancak, E., Kocak, D., Yuksek, M. Effect of Applied Different Surface Modification Processes with Cellulose Enzyme on Properties of Luffa Fibres Asian Journal of Chemistry 24 (3) 2012: pp. 975-980.

25. Yuksek, M. Effect of Degumming Performed with Different Type Natural Soaps and Through Microwave Energy Method on the Properties of Silk Fiber Asian Journal of Chemistry 24 (2) 2012: pp. $742-746$.

26. Pejic, B.M., Kostic, M.M., Skundric, P.D., Praskalo, J.Z. The Effects of Hemicelluloses and Lignin Removal on Water Uptake Behaviour of Hemp Fibers Bio Resource Technology 99 (15) 2008: pp. $7152-7159$.

27. Li., Y., Pickering, K.L. Hemp Fibre Reinforced Composites Using Chelator and Enzyme Treatments Composites Science and Technology 68 2008: pp. 3293-3298.

28. Kocak, D., Merdan, N., Evren, O.B. Research into the Specifications of Woven Composites Obtained from Raffia Fibers Pre-Treated Using the Ecological Method Textile Research Journal 85 (3) 2015: pp. 302-315.

29. Abou-Okeil, A., El-Shafie, A., El Zawahry, M.M. EcoFriendly Laccase-Hydrogen Peroxide/Ultrasound-Assisted Bleaching of Linen Fabrics and its Influence on Dyeing Efficiency Ultrasonics Sonochemistry 17 (2) 2010: pp. $383-390$

30. Sun, D., Guo, Q., Liu, X. Investigation into Dyeing Acceleration Efficiency of Ultrasound Energy Ultrasonics 50 (4-5) 2010: pp. 441-446.

31. Antonov, V., Marek, J., Bjelkova, M., Smirous, P., Fischer, H. Easily Available Enzymes as Natural Retting Agents Biotechnology Journal 2 2007: pp. 342-346.

32. Buyukakinci, Y., Sokmen, N., Oner, E. Improving the Dyeability of Polyolefin Fibres by Microwave Heating Industria Textile 65 (4) 2014: pp. 228-232. 